\title{
De los micrómetros a los picómetros: evolución de las técnicas de microscopía para el estudio de nanomateriales
}

\section{From micrometers to picometers: evolution of microscopy techniques for the study of nanomaterials}

\author{
Margarita Rivera*,1 y Jesús Arenas-Alatorre*
}

\begin{abstract}
Over the last few decades, electron microscopy (EM) and scanning probe microscopy (SPM) techniques have had a great contribution to the study of nanomaterials in many research fields, providing morphological, structural, interfacial, electric and magnetic information, among many others. Recent technological advances of these techniques have helped to achieve unprecedent spatial resolution limits unimaginable 25 years ago, being the last reported values of tenths of picometers $\left(10^{-12} \mathrm{~m}\right)$. In addition, these techniques have grown in analytical capabilities in the nanoscience and nanotechnology fields, resulting in new independent, or even complimentary, techniques that have improved the understanding of interaction phenomena and physicochemical properties at the atomic and molecular scale. In this paper, an analysis of the actual importance of these techniques as well as some of their recent characterization and analytical achievements are discussed. Finally, in view of its enormous progress and large potential in the study and understanding of physical and chemical processes at the nanoscale, future challenges and perspectives are underlined.
\end{abstract}

KEYWORDS: scanning electron microscopy (SEM), field emission electron microscopy (FSEM), transmission electron microscopy (TEM), high resolution-high angle annular dark field (HR-HA$A D F)$, scanning transmission electron microscopy (STEM), atomic force microscopy (AFM), scanning tunneling microscopy (STM), scanning tunneling spectroscopy (STS), magnetic force microscopy (MFM).

RESUMEN: En las últimas décadas, las técnicas de microscopía electrónica (EM) y microscopía de barrido por sonda (SPM) han contribuido enormemente al estudio de nanomateriales en muchos campos de investigación, dando información de propiedades morfológicas, estructurales, de superficie, eléctricas y magnéticas, entre muchas otras. Los avances tecnológicos recientes asociados con estas técnicas han permitido alcanzar límites de resolución espacial que hace 25 años era inimaginables, siendo los últimos valores reportados de decenas de picómetros $\left(10^{-12}\right.$ m). Adicionalmente, estas técnicas han crecido en sus capacidades de análisis en el campo de las nanociencias y nanotecnología, dando lugar a otras microscopías independientes, o incluso complementarias, que han contribuido al entendimiento de fenómenos de interacción y propiedades fisicoquímicas a escalas atómicas y moleculares. En este articulo, se hace un análisis de la trascendencia actual que tienen las técnicas de microscopía electrónica y de microscopia de barrido por sonda, y se mencionan brevemente algunos de sus alcances actuales como métodos

Recibido: 28 de septiembre de 2018.

Aceptado: 10 de diciembre de 2018.

* Universidad Nacional Autónoma de México, Instituto de Física, Ciudad de México, México.

${ }^{1}$ Autora de correspondencia: mrivera@física.unam.mx 
de caracterización y análisis. Finalmente, se señalan algunas retos, así como perspectivas, en cuanto a su enorme potencial para impulsar el estudio y entendimiento de procesos fisicos y químicos a nanoescala.

PALABRAS CLAVE: microscopía electrónica de barrido, microscopía electrónica de barrido de emisión de campo, microscopía electrónica de transmisión, campo oscuro anular a ángulo grande en alta resolución, microscopía electrónica de transmisión de barrido, microscopía de fuerza atómica, microscopía de efecto tunel, espectroscopía de tunelamiento de barrido, microscopía de fuerza magnética.

\section{Introducción}

Los inicios de la nanociencia y nanotecnología están estrechamente relacionados con el físico teórico Richard Feynman, premio Nobel de Física en el año 1965, por sus aportaciones en la electrodinámica cuántica. Feynman, en 1959, durante su famosa conferencia "There's plenty of room at the bottom" (Hay mucho espacio en el fondo), en la reunión de la Sociedad Americana de Física, habló de la materia a escala atómica y molecular, y mencionó la siguiente frase premonitoria de la nanotecnología: "Nada en las leyes conocidas de la física impide que se puedan escribir los 24 volúmenes de la Enciclopedia Británica en algo tan diminuto como la cabeza de un alfiler, construir una maquinaria de tamaño molecular, y herramientas de cirugía capaces de introducirse en el cuerpo del paciente y operar desde el interior de sus tejidos", (Ralph Merkle, 2018). Estas frases provocaron inicialmente más risas que admiración, tal es así, que el artículo resultado de ese trabajo tuvo sus primeras citas hasta el año 1980. Por otra parte, estas palabras fueron un desafío para mejorar la resolución del microscopio electrónico (EM), ${ }^{2}$ que en el año 1959 era del orden de 5 $\mathrm{nm}$, y crear el microscopio de efecto tunel (STM), que se dio a conocer hasta el año 1981 por Gerd Binnig y Heinrich Rohrer, investigadores de la IBM Research Divison (Binnig, 1982). Lo anterior, demostró que Feynman tenía toda la razón al decir que no hay nada en las leyes de la física que impida interaccionar con átomos, e incluso manipularlos, para crear estructuras tales como letras, en alusión a las siglas de IBM que dejaron plasmadas Donald Eigler y Erhard Schweizer en 1989 en una superficie de níquel usando 35 átomos de Xe.

Para el caso de la microscopía electrónica, en la figura 1 se muestra un esquema de cómo ha ido evolucionando su resolución espacial (Pennycook, 2006). Como se observa, la microscopía de luz llegó a su límite de resolución en el año de 1872, con la teoría desarrollada por Ernst Abbe. En ella, se establecen las condiciones que deben satisfacer las lentes de un sistema óptico para generar imágenes nítidas y libres de aberraciones esféricas, cromáticas y coma. En particular, la aberración esférica (Cs) y la longitud de onda $(\lambda)$ son las limitantes principales de la resolución (R) de un microscopio, sea de luz o electrónico $\left(\mathrm{R} \sim \lambda^{3 / 4} \mathrm{Cs}^{1 / 4}\right)$.

\footnotetext{
${ }^{2}$ La lista completa de acrónimos usados se encuentra al final del artículo.
} 
Recordemos que la aberración esférica es inherente a cualquier tipo de lente, sea de vidrio o electromagnética, y consiste en que los rayos paraxiales (los que pasan cerca del eje óptico) difieren en su punto focal con respecto a los rayos marginales (los cuales pasan más alejados del eje óptico). A la distancia que separa el foco de los rayos paraxiales y marginales, se le conoce como constante de aberración esférica (Cs), la cual puede ser disminuida únicamente por los fabricantes de microscopios. Dado que la longitud de onda en el espectro visible es de centenares de nanómetros, y considerando la minimización de la aberración esférica gracias a la teoría de Abbe, la microscopía de luz llegó a su límite de resolución en centenares de nanómetros en el año 1880, siendo Karl Zeiss el fabricante del instrumento. Desafortunadamente, con la resolución que nos brinda un microscopio de luz, poco se puede saber sobre las propiedades estructurales y morfológicas de sistemas nanoestructurados.

El primer EM fue el de transmisión (TEM), y fue construido entre 1925 y 1933 en Berlín, Alemania, por Ernts Ruska (en aquel entonces estudiante de doctorado) y Max Knoll (tutor de Ruska). El microscopio como tal se dio a conocer en el año 1933, tenía una resolución apenas 10 veces mayor a la de un microscopio de luz, lo cual se asoció con las grandes aberraciones de las lentes electromagnéticas utilizadas y al bajo voltaje empleado. Debido a ello, el microscopio electrónico no tuvo un interés inicial para su uso en las diferentes ramas de la ciencia, sin embargo, el logro más importante de Ruska y Knoll fue demostrar que era posible formar imágenes con electrones.

Gracias al alcance de análisis que tenía el EM, en el año de 1986, con una resolución menor a $2 \AA$ (0.2 nm), Ruska recibe el premio Nobel de Física junto con Binnig y Rohrer (desafortunadamente, Knoll había fallecido dos años antes), con lo cual se reconoció el gran aporte científico que hicieron él y Knoll en el estudio de materiales orgánicos e inorgánicos para estudiar la forma, distribución de tamaño y estructura cristalina de nanopartículas (NPs). Actualmente, el EM se sigue desarrollando de manera inimaginable, tan es así, que hoy en día se tienen equipos de TEM con resolución de subangstroms (0.05 nm o 50 pm), y microscopios electrónicos de barrido (SEM) con resolución de $0.5 \mathrm{~nm}$, lo que los convierte en herramientas prioritarias en el estudio de sistemas nanométricos (Pennycook, 2006; Oxley, 2017).

En la figura 1, se describen brevemente los alcances que tienen hoy en día los microscopios electrónicos y de SPM, en sus diferentes modalidades y técnicas analíticas asociadas.

\section{Microscopía electrónica de transmisión (TEM)}

Desde su aparición, el TEM ha tenido un avance vertiginoso, no solo desde el punto de vista de la resolución espacial alcanzada, que gracias a los avances en los correctores de aberración esférica llega a 50 pm (0.05 nm), sino también por los modos de operación con los que cuenta. Un TEM moderno trabaja con voltajes de aceleración en el intervalo de $100-300$ kV. La ilumina- 
Mundo Nano | ARTículos DE REVISión | www.mundonano.unam.mx

12(23), 1e-25e, julio-diciembre 2019 | http://dx.doi.org/10.22201/ceiich.24485691e.2019.23.67334

Margarita Rivera y Jesús Arenas-Alatorre

FIGURA 1. Cronología del desarrollo de la microscopía de luz y electrónica.

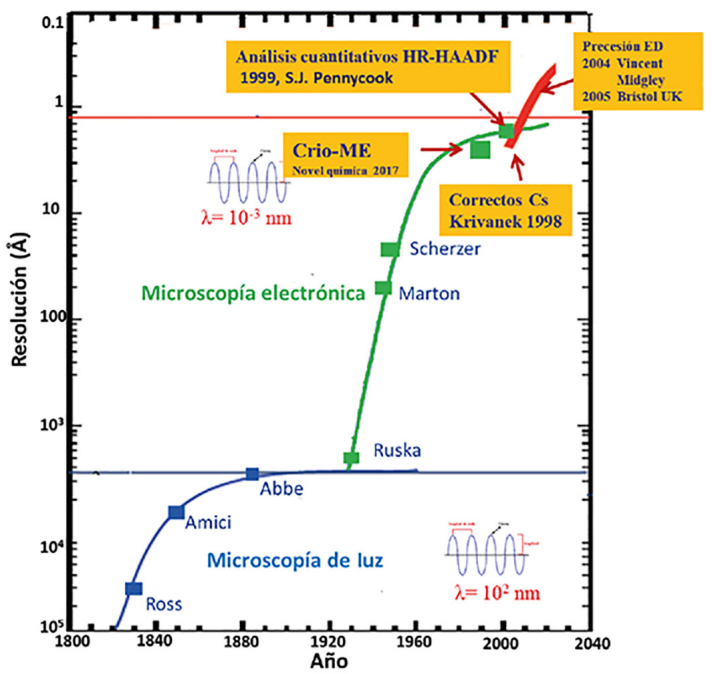

Fuente: Fuente: Adaptado de Pennycook (2006).

ción es proporcionada por un cañón de electrones que consiste de un cátodo de emisión termoiónica de $\mathrm{W}\left(\mathrm{o}, \mathrm{LaB}_{6}\right)$, el cual proporciona un haz de electrones cuasi-monocromático y poco coherente, o por un cañón de electrones por emisión de campo, el cual proporciona un haz monocromático y de alta coherencia espacial (filamento $\mathrm{W}$ recubierto con $\mathrm{ZrO}_{2}$ ). Una vez emitido el haz de electrones, pasa a través de varias lentes electromagnéticas (condensadoras, objetivas y proyectoras), no sin antes pasar por la muestra de interés que se coloca entre las lentes condensadora y objetiva. El resto de las componentes son lentes proyectoras que amplifican la imagen consecutivamente. La imagen se proyecta finalmente sobre una pantalla fluorescente, vista a través de una ventana de vidrio. Debajo de la pantalla se encuentra una cámara CCD o cámara fotográfica, la cual debe estar en vacío al igual que el resto de la columna del microscopio (entre $10^{-6}-10^{-9}$ torrs).

Los modos de operación asociados con un TEM de última generación son más de 12. Entre ellos se tienen los siguientes: campo claro (CTEM), campo oscuro (DFTEM), microscopía electrónica de transmisión de alta resolución (HRTEM), microdifracción ( $\mu$ Diff), difracción de electrones por haz convergente (CBED), patrón de difracción con precesión de electrones, campo oscuro anular a ángulo grande (HAADF), campo oscuro anular a ángulo grande en alta resolución (HR-HAADF), microscopía electrónica de transmisión por barrido (STEM), Crio-TEM, holografía electrónica, tomografía electrónica, y las técnicas analíticas espectroscopía por dispersión de energía de rayos $\mathrm{X}$ (EDS) y espectroscopía por pérdida de energía de electrones (EELS) con su respectiva capacidad para realizar mapeo de elementos. 
A continuación, se abordarán las técnicas más utilizadas en nanociencias y nanotecnología: CTEM, HRTEM, HAADF, HR-HAADF, EELS y STEM, con la intención de mostrar algunos ejemplos de su aplicación, así como sus alcances y limitaciones en el análisis de sistemas nanoestructurados. Para una mayor profundidad en la teoría de cada una de estos modos de operación de un TEM, se recomienda consultar el libro de William (2009), y el de Bell (2013).

\section{Microscopía electrónica de transmisión de alta resolución (HRTEM)}

Cuando se realiza la síntesis de un material nanométrico, frecuentemente nos hacemos las siguientes preguntas; ¿realmente sintetizamos nanopartículas?; ¿cuál es la distribución de tamaño de partícula?; ¿cómo está distribuida dentro de una matriz y como es la interacción nanopartícula-soporte (si es el caso)?; ¿cuáles son sus posibles formas?; ¿qué fase cristalina tienen?, entre otros. TEM responde a estas preguntas en sus modalidades de CTEM, HRTEM, STEM, HAADF y HR-HAADF. En la figura 2a, se muestra la trayectoria del haz electrónico al interaccionar con la muestra bajo observación en los modos de operación CTEM y HRTEM. Para una muestra cristalina, la imagen de HRTEM es el resultado de un proceso de interferencia de los ha-

FIGURA 2. a) Formación de imagen HRTEM de un material cristalino. b) Arreglo de los diferentes detectores en una unidad STEM, campo claro (BF), campo oscuro (ADF) y campo oscuro anular a ángulo grande (HAADF). c) Vista en 3D del detector anular HAADF e imágenes obtenidas en STEM en los modos $\mathrm{BF}$ y $\mathrm{HR}-\mathrm{HAADF}$ del compuesto $\mathrm{BiFeO}_{3}$; en la imagen HR-HAADF de marco azul, los átomos brillantes son de $\mathrm{Bi}$ (bismito) y los menos brillantes de Fe (fierro). La imagen con marco rojo de campo claro muestra columnas de oxígeno. La imagen en marco verde corresponde a una muestra de $\mathrm{LaMnO}_{3}$ por EELS, donde el Mn se muestra en rojo, $O$ en verde y La en azul.
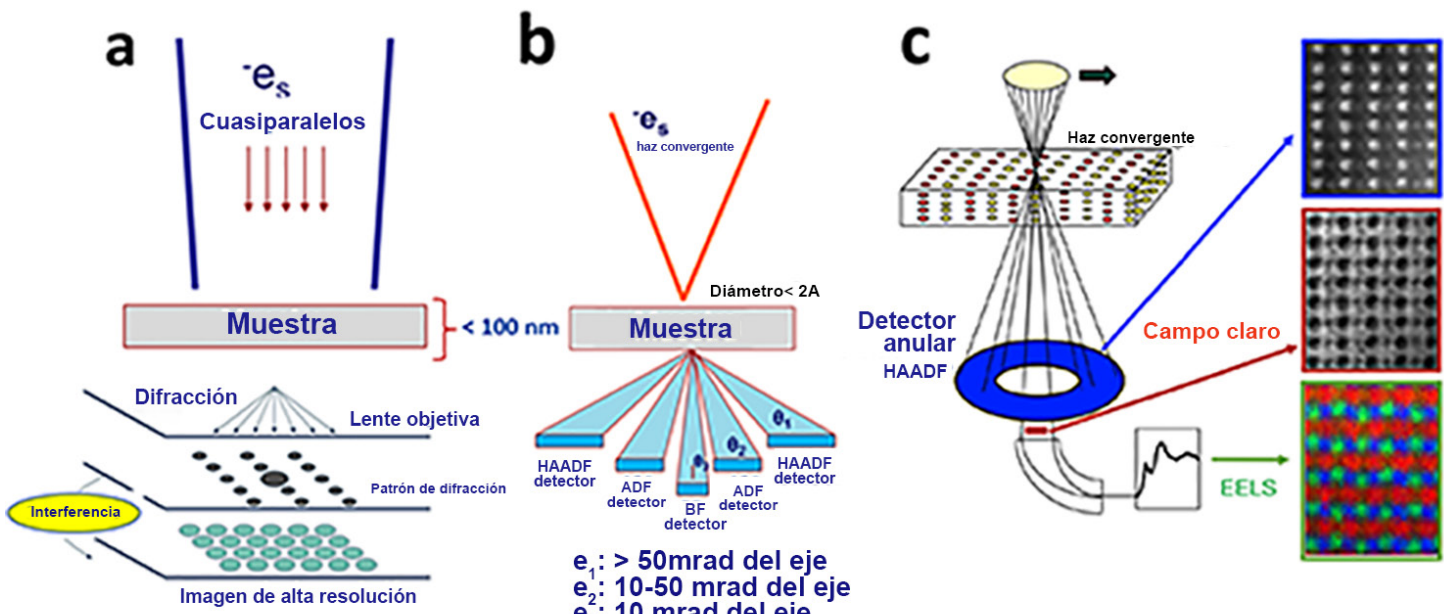

$e_{1}:>50$ mrad del eje

$e_{2}^{1}: 10-50$ mrad del eje

$\mathrm{e}_{3}: 10$ mrad del eje

Fuente: Las imágenes $2 \mathrm{a}$ y $2 \mathrm{~b}$ son diseño de los autores, la imagen $2 \mathrm{c}$ fue tomada de J. Pennycook (2018). 
ces difractados. Se debe hacer notar que en este modo de operación, un haz electrónico fijo casi paralelo ilumina la muestra, lo cual puede llegar a ser un problema, pues debido a la interacción electrones-muestra, las nanopartículas y/o películas delgadas pueden vibrar, desplazarse, girar e incluso cambiar de forma durante el estudio afectando la calidad de los resultados. Para evitar estos problemas, la preparación de la muestra se vuelve un factor determinante en los resultados que se obtienen. En la figura $2 \mathrm{~b}$ se muestra el arreglo de los diferentes detectores en una unidad STEM, y en la figura 2c, un esquema y tipo de imágenes obtenidas con el detector anular HAADF.

En la figura 3a se muestra un ejemplo de una imagen típica de los años 80 y 90 del siglo pasado obtenida por CTEM de nanopartículas de $\mathrm{Pt} / \mathrm{SiO}_{2}$ a $100 \mathrm{kX}$ para estudiar su tamaño y distribución. Sin lugar a duda información importante, pero limitada para las exigencias de hoy en día. En la figura 3b, se muestra una imagen adquirida por HRTEM de una nanopartícula de $\mathrm{Au}$ de $20 \mathrm{~nm}$ de forma decaedral obtenida a $500 \mathrm{kX}$ con su respectivo modelo en 3D (figura 3c). Cabe señalar que la morfología en ocasiones es difícil de determinar, pues una imagen de TEM es una proyección en dos dimensiones de un objeto que tiene forma tridimensional. A pesar de esto, la posible forma tridimensional de una nanopartícula se determina con base en las maclas observadas (que en realidad son las aristas de la nanopartícula), a la orientación de la red cristalina y a la forma del contorno de la nanopartícula, tal como se muestra en figura $3 \mathrm{~b}$. Tomando en cuenta lo anterior, técnicas como STEM, HAADF y HR-HAADF han adquirido una gran relevancia en el análisis de sistemas nanoestructurados.

\section{Microscopía electrónica de transmisión por barrido (STEM) y campo oscuro anular a ángulo grande (HAADF)}

El funcionamiento de un STEM es similar al de un SEM, en ambos casos el haz de electrones es enfocado sobre la superficie de la muestra y la barre con

FIGURA 3. a) Imagen de CTEM de Pt/SiO ${ }_{2}$, obtenida a $100 \mathrm{kX}$. b) Imagen obtenida por HRTEM a $500 \mathrm{kX}$ de una nanopartícula de Au de forma decaedral.

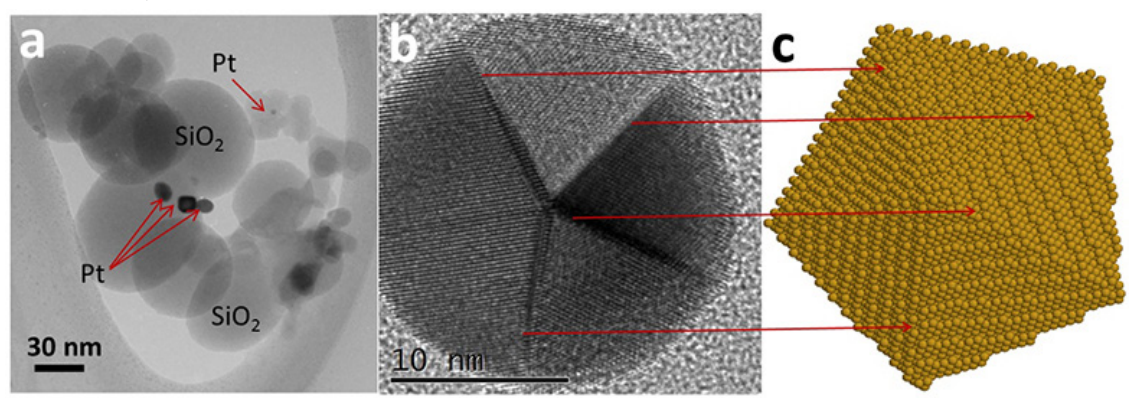

Fuente: Cortesía del Dr. Samuel Tehuacanero. c) Modelo tridimensional de la partícula realizado con el software crystal. 
la ayuda de la bobina deflectora. Al pasar el haz de electrones por cada punto de la muestra produce diferentes señales que son detectadas, en el caso de STEM, por detectores colocados por debajo de la muestra, en tanto que en SEM, los detectores están colocados por arriba de la misma. En el caso de STEM, el haz de electrones debe tener, de preferencia, un diámetro menor a $0.02 \mathrm{~nm}$ y el espesor de la muestra no debe ser mayor a $100 \mathrm{~nm}$, mientras que en SEM, el diámetro del haz está entre $5 \mathrm{~nm}$ y $200 \mathrm{~nm}$.

Con base en lo expuesto y con la aparición a finales del siglo pasado de las tecnologías de emisión de campo, los correctores de aberración esférica y al aumento de la relación señal/ruido, hoy en día STEM se ha convertido en la técnica de microscopía más utilizada en la investigación de sistemas nanoestructurados. La resolución actual alcanzada es del orden de $50 \mathrm{pm}$. Antes de la aparición de los correctores de aberración esférica y equipos de emisión de campo, era difícil introducir suficiente corriente en la sonda (haz de electrones enfocado en la muestra) para obtener imágenes de buena calidad, ni siquiera se podían obtener señales espectroscópicas a resolución atómica. Los correctores de aberración esférica vinieron a proporcionar sondas más pequeñas y brillantes, con lo que se ha superado la desventaja histórica del STEM, que es la de una baja relación señal/ruido (Oxley, 2017). En STEM, el haz de electrones incidente se enfoca en un punto fino sobre la muestra, proporcionando varias señales que son detectadas por debajo de esta de manera secuencial y que brinda imágenes con características complementarias, tales como BF, ADF, HAADF, EDS y mapeos químicos (con EELS o la unidad EDS) (figuras 2c y 4 ).

FIGURA 4. a) Imagen obtenida por STEM en modo HAADF, de dos nanopartículas del catalizador bimetálico $\mathrm{Ni}-\mathrm{Pt} / \mathrm{SiO}_{2}$. Los gráficos sobrepuestos indican el análisis químico realizado a lo largo de la línea de color rosa donde se muestra que ambas partículas contienen platino (línea azul) y níquel (línea roja). b) Mapeo químico de Pt (en azul) y Ni (en rojo).
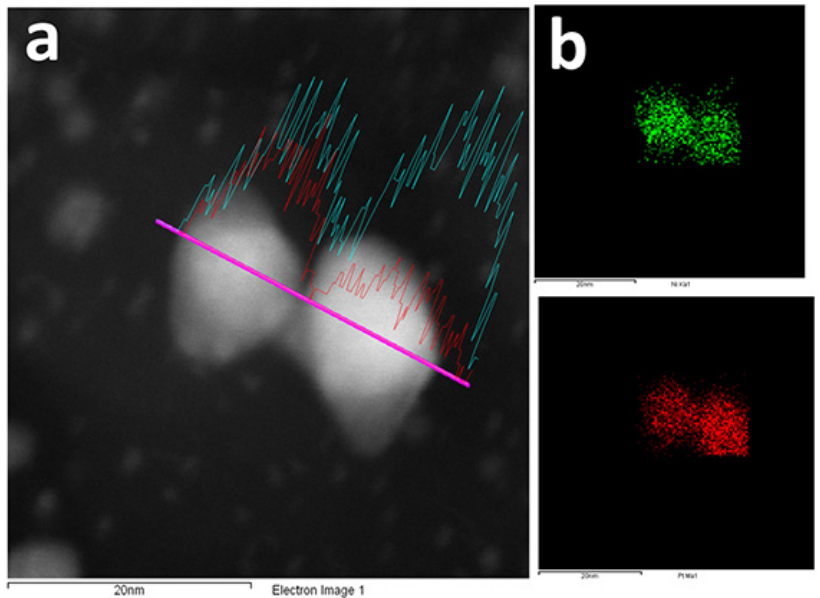

Fuente: Cortesía del Dr. Álvaro Ángeles P., CINVESTAV-Zacatenco. 
Por otro lado, el detector de HAADF recoge la dispersión que se da a ángulos grandes respecto al haz incidente, conocida como dispersión de Rutherford, la cual se da cuando los electrones pasan cerca del núcleo atómico de la muestra y son desviados a ángulos grandes respecto a su trayectoria inicial. Por ser esta señal proporcional al cuadrado del número atómico (Z) (Pennycook, 2018), se produce una imagen con una alta sensibilidad a los elementos presentes en la muestra. En sitios donde haya elementos más pesados se observarán zonas más contrastadas, es por ello que a esta técnica también se le conoce como "contraste Z".

Otra razón por la que STEM en su modalidad HR-HAADF ha tenido una gran aceptación entre los usuarios de un TEM, es porque en comparación con HRTEM, el haz de electrones es menos agresivo para la muestra dada su característica de capturar secuencialmente la imagen al igual que un SEM. Además, es menos sensible a las inclinaciones de muestras cristalinas y a su grosor; por lo que puede proporcionar posiciones de columnas atómicas con alta precisión (Pennycook, 2018). Actualmente, con software especializado como el STEMcell (Grillo, 2013) basado en la teoría de multicapas de formación de imágenes de STEM (Kirkland, 2009), se puede predecir el número de átomos contenidos en cada columna atómica en base a un análisis de intensidades tal como se muestra en la figura 5 a, donde se presenta una partícula cúbica de Ir (Iridio) de 4x4x4 átomos. Los gráficos de la figura 5b corresponden a las intensidades en unidades arbitrarias a lo largo del arreglo de puntos altamente contrastados de las áreas indicadas. Cada punto representa una columna de átomos, y, dado que la intensidad es casi la misma, se concluye que la partícula es cúbica.

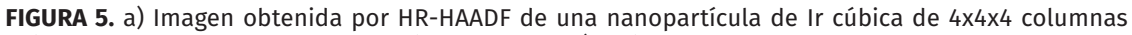
atómicas con su respectiva simulación molecular. b) Análisis de intensidades sobre los dos arreglos de puntos altamente contrastados mostrados en $5 a$.
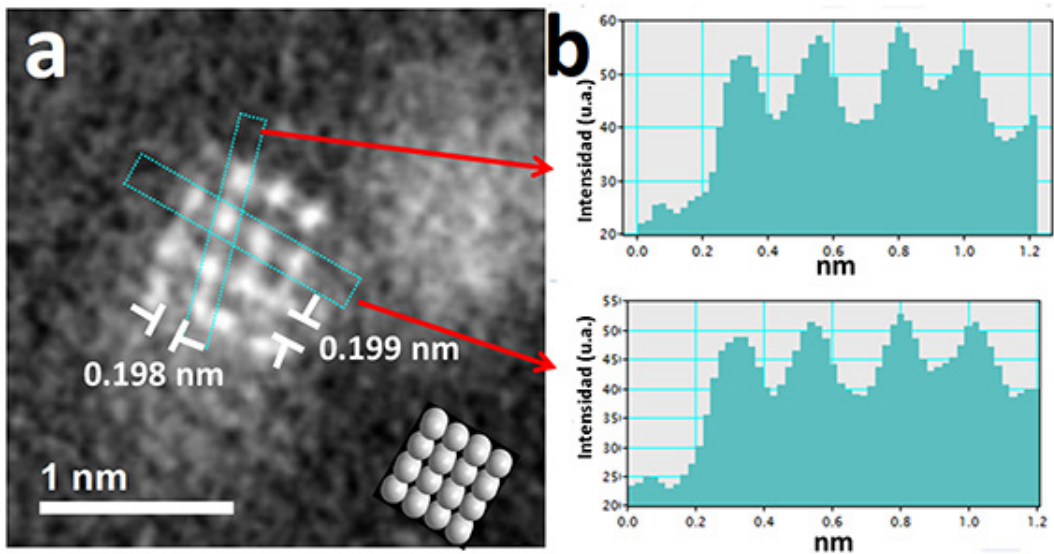

Fuente: Cortesía de la Dra. Gabriela Díaz G., IFUNAM. 


\section{Espectroscopía por pérdida de energía de electrones (EELS)}

La espectroscopía de pérdida de energía de electrones (EELS), basada en el análisis de distribución de la pérdida de energía de los electrones que interactúan inelásticamente con la materia, también ha aumentado sus alcances de análisis con la aparición de los correctores de aberración esférica. Hoy en día, proporciona información invaluable sobre composición y estructura electrónica a escala atómica, y se puede obtener simultáneamente junto con la imagen de HR-HAADF (Varela, 2004). Su gran sensibilidad permite la identificación espectroscópica de un solo átomo dentro de un material estudiando su entorno electrónico local, tal como se ejemplifica en la figura 2c. Este nivel de análisis representa el último avance para comprender los orígenes atómicos de las propiedades de los materiales.

De manera adicional, en los últimos años, otros métodos de operación por TEM, como la tomografía electrónica, han logrado avances importantes para determinar la forma de las nanopartículas en tres dimensiones (Sandra Van Aert, 2011; Chen, 2003). En este modo de operación, la reconstrucción en 3D se calcula a partir de una serie de imágenes proyectadas que se adquieren al inclinar la muestra. La resolución espacial para la reconstrucción es de alrededor de un nanómetro cúbico, lo cual limita su uso para lograr una resolución atómica. Otra técnica potencial con la que se ha tratado de hacer la reconstrucción 3D es a través del llamado "corte en profundidad", en el mismo una muestra se corta ópticamente cambiando el enfoque de la lente objetivo. Con esta técnica se pueden visualizar átomos individuales, pero no se han mostrado las reconstrucciones 3D en resolución atómica, debido a que la resolución en profundidad es insuficiente para resolver distancias interatómicas a lo largo del eje óptico

Por otra parte, la crio-microscopía, en donde la muestra bajo estudio se congela en fracciones de segundo y cuyo mayor impacto se encuentra en las áreas biológicas y médicas, tiene la capacidad de resolver estructuras moleculares y biológicas de hasta $0.2 \mathrm{~nm}$ (Stewart, 2017). Esta última técnica fue desarrollada por Jacques Dubochet, Joachim Frank y Richard Henderson, quienes fueron galardonados con el premio Nobel de Química 2017.

\section{Microscopía electrónica de barrido (SEM)}

Manfred von Ardenne, en el año 1938, desarrolló el primer SEM con el propósito de estudiar la superficie de los materiales. El primer SEM comercial fue distribuido en 1965 por la compañía británica Cambrige Instruments. Un SEM presenta ventajas respecto a un microscopio óptico, debido al uso de un mayor número de señales provenientes de la interacción de los electrones con la muestra (electrones secundarios, retrodispersados, rayos X característicos, electrones Auger y catodoluminisencia), y que proveen informa- 
ción sobre la topografía, la orientación cristalina, la composición química, y el potencial eléctrico del material en observación (Mcmullan D., 1995). A diferencia del TEM, en donde los detectores se encuentran por debajo de la muestra, los detectores de SEM se encuentran por arriba de esta.

En los años 90, aparecieron tecnologías interesantes en el diseño de un SEM, entre ellas, la tecnología ambiental (ESEM) y de bajo vacío (LV-SEM), lo cual benefició enormemente los campos de ciencias biológicas, arqueológicas, y cerámicos, entre otros. Sin embargo, la resolución espacial alcanzada por estos equipos en las mejores condiciones de uso es de $3 \mathrm{~nm}$, aún insuficiente para estudiar materiales nanoestructurados. A pesar de esto, en el campo de nanociencias, un SEM de este tipo se utiliza básicamente para el estudio de morfologías y para la obtención de información química elemental por EDS o WDS. A principios de siglo, con la comercialización de la tecnología de emisión de campo (FSEM) se comenzaron a ofrecer comercialmente equipos cuya resolución espacial estaba por debajo de $1 \mathrm{~nm}$, y con mayor rapidez de adquisición, lo cual abrió su uso para las nanociencias. Hoy en día, se tienen equipos comerciales con resolución de $0.5 \mathrm{~nm}$ adecuados para estudiar materiales nanoestructurados que están equipados con unidad STEM, EDS, WDS, XRF, EBSD y $\mu$-Raman. En la figura 6, se muestra una imagen típica de FSEM y STEM de nanopartículas de óxidos de zinc y nanopartículas de $\mathrm{Ag}$ (plata) menores a $100 \mathrm{~nm}$, respectivamente.

Otras innovaciones hacia la alta resolución en un SEM han sido el acortamiento de la distancia de trabajo (WD) a 2-3 mm entre la lente objetiva y la muestra, y la presencia de otros detectores en la cámara del microscopio que dan información complementaria (Borrajo-Pelaez R. 2018).

Hasta ahora, el uso de correctores de aberración esférica en un SEM no ha sido viable debido a dificultades en su alineación, y a la reducción de profundidad de campo de la imagen debido a la abertura mucho más grande en este tipo de lentes. No obstante, hay propuestas de correctores de aberración

FIGURA 6. a) Nanopartícula de óxidos de zinc menores a $100 \mathrm{~nm}$ observadas en un equipo FSEM. b) Imágenes vista por STEM en campo oscuro de nanopartículas de Ag. Las formas regulares menos contrastadas corresponden a $\mathrm{AgNO}_{3}$.
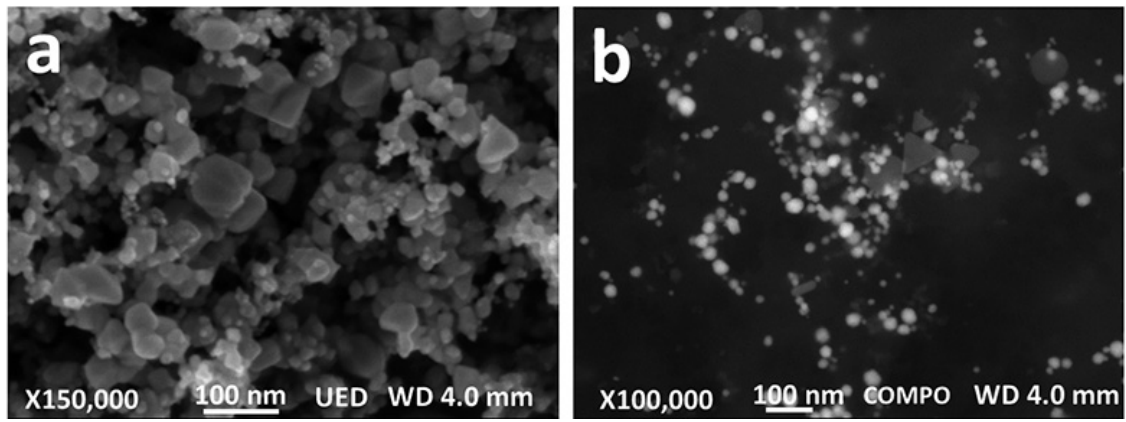

Fuente: Elaboración de los autores. 
esférica y cromática, aunque su utilidad aún no se ha mostrado en el estudio de nanomateriales.

\section{Microscopio de haz de iones focalizado (FIB)}

Un instrumento que ha venido a revolucionar a la microelectrónica y nanotecnología, por su capacidad de manipular la materia a escala nanométrica es el FIB, el cual fue dado a conocer por Levi-Setti en el año 1974. El FIB es un instrumento que se ve y funciona como un SEM, ya que ambos instrumentos se basan en un haz enfocado para crear una imagen de la muestra, siendo un haz de iones para el FIB y un haz de electrones para el SEM. Adicionalmente, el FIB puede ser usado para erosionar una superficie con precisión nanométrica para el procesamiento de muestras y la fabricación de nanoestructuras (figura 7). A pesar de existir gases halógenos como el $\mathrm{Cl}_{2}, \mathrm{I}_{2}$, o $\mathrm{XeF}_{2}$ que mejoran la rapidez de pulverización catódica, el uso de iones de $\mathrm{Ga}^{+}$ (Galio) es ventajoso en estos equipos por dos razones: (a) el Ga tiene un punto de fusión bajo y, por lo tanto, existe en estado líquido cerca de la temperatura ambiente, y, (b) el Ga puede enfocarse a un tamaño de sonda muy fino (10 nm de diámetro). En general, los FIB suelen funcionar con voltajes de aceleración entre 5 y $50 \mathrm{keV}$, ocasionando la eyección de partículas pulverizadas y la implantación de iones $\mathrm{Ga}^{+}$a una profundidad de penetración 20 nm para $25 \mathrm{keV}$ (Giannuzzi, 1999).

FIGURA 7. Imagen obtenida por SEM, donde se muestra el desbaste con el haz de iones de Galio de una muestra de GaSb/GalnAsSb/GalnAsSb.

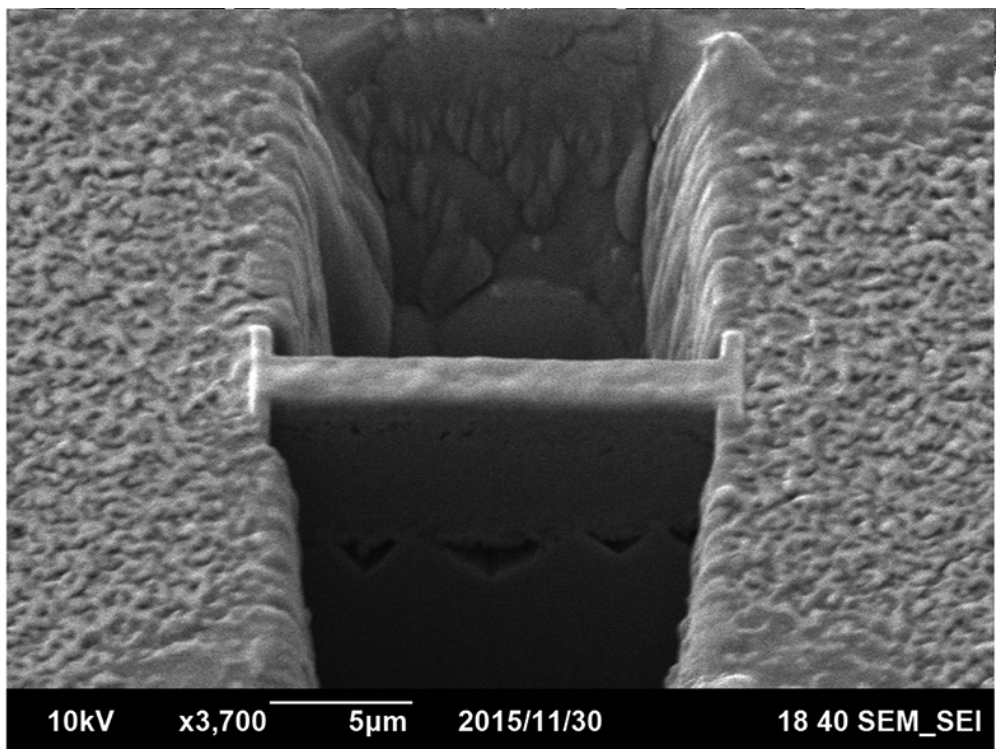

Fuente: Cortesía Dr. Alvaro Ángeles P., CINVESTAV-Zacatenco. 


\section{Microscopía de barrido por sonda (SPM)}

La microscopía de barrido por sonda (SPM) engloba una familia muy grande de técnicas (figura 8), las cuales basan su funcionamiento en medir la interacción entre una sonda o punta muy fina y una muestra, permitiendo estudiar propiedades locales de superficies con resolución atómica. Entre las grandes ventajas de este tipo de microscopías se encuentran su gran resolución espacial, su capacidad para trabajar en medios diversos tales como en aire, líquidos, ultra-alto vacío, atmósferas controladas, altas y bajas temperaturas, por mencionar algunos y, por último, su eficacia para generar imágenes reales en 3D. Adicionalmente, debido a que todos estos estudios se realizan bajo interacciones muy débiles, el daño a la muestra es casi nulo, dando la posibilidad de realizar estudios de cinéticas de transformación de superficies en tiempo real (Schitter, 2008).

De manera general, los microscopios SPM están conformados por tres partes fundamentales: a) la sonda, b) el sistema de barrido y mecanismo de retroalimentación, y, c) los controles electrónicos. Cada una de estas partes contribuye de manera determinante en la resolución espacial que se alcanza, así como en el tipo y magnitud de la interacción que se miden (Sharma, 2016). En este escrito, sería imposible resumir los tipos y logros de todas las técnicas SPM que se manejan actualmente, a tal efecto se mencionarán únicamente las técnicas más relevantes que son la microscopía de efecto túnel (STM) y la de fuerza atómica (AFM) (figura 9), así como sus alcances recientes que han revolucionado la forma de estudiar y cuantificar un gran número de propiedades de superficies e interfaces.

FIGURA 8. Algunos ejemplos de técnicas pertenecientes a la familia SPM. Las técnicas correspondientes a cada acrónimo se listan al final del texto.

\section{Scanning Probe Microscopy}

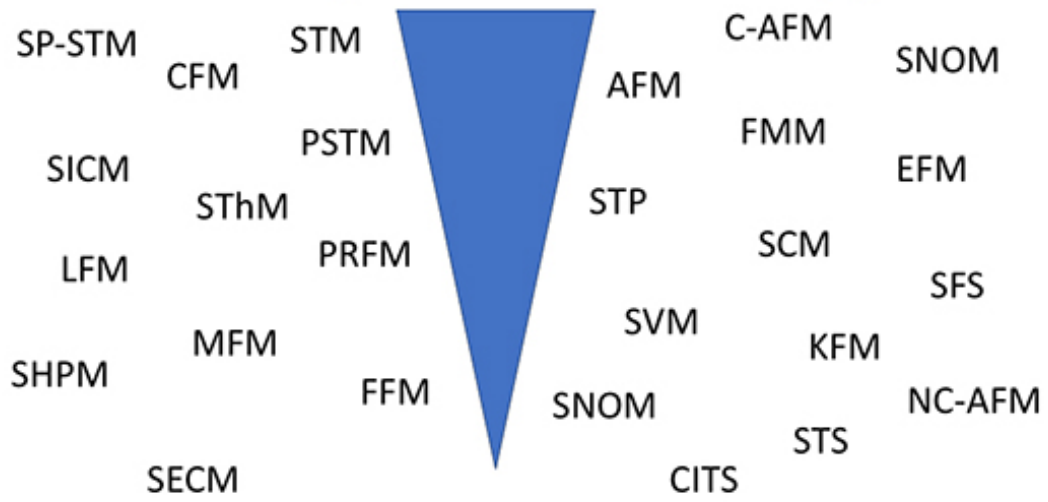

Fuente: Elaboración de los autores. 
FIGURA 9. Esquemas de funcionamiento de los microscopios STM y AFM.

Microscopio de efecto tunel

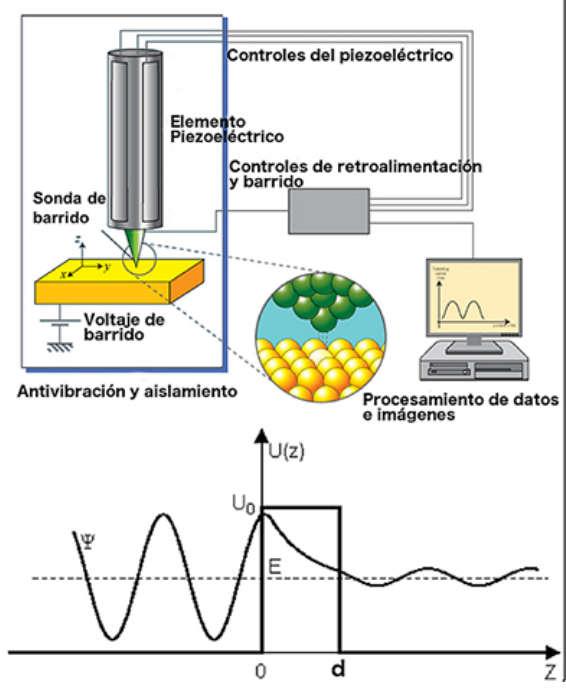

Microscopio de fuerza atómica
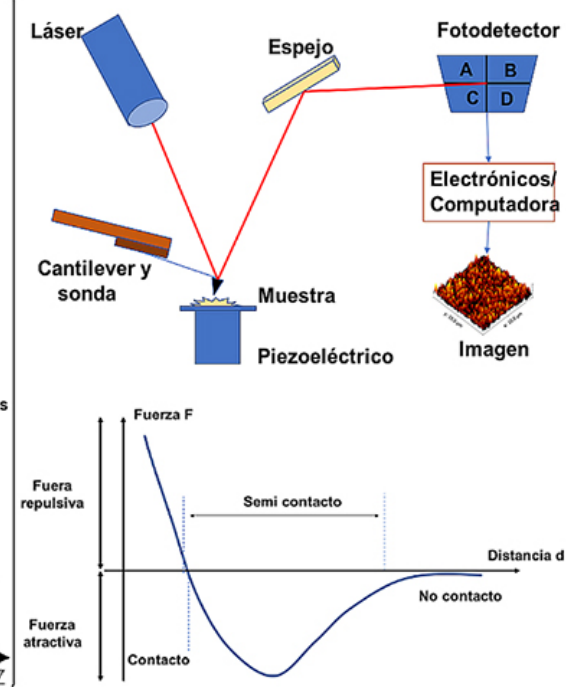

Fuente: Figura STM modificada de www.hk-phy.org

\section{Microscopía y espectroscopía de tunelamiento (STM y STS)}

El STM fue el primer microscopio de esta familia (Binnig, 1982), y sigue siendo un referente en el estudio de estructuras y fenómenos a escala atómica. Este microscopio basa su funcionamiento en el fenómeno de tunelamiento cuántico, efecto por el cual, los electrones pasan entre una muestra conductora y una punta o sonda (también conductora), cuando se encuentran a distancias menores a $10 \AA$, bajo la influencia de una diferencia de potencial del orden de $\mathrm{mV}$. En este contexto, la separación entre conductores representa una barrera de potencial, y como resultado se obtiene una corriente eléctrica muy pequeña $(\sim \mathrm{nA})$, cuyo valor depende esencialmente de la distancia entre electrodos. El modelo matemático más aceptado para representar la corriente de tunelaje muestra una dependencia lineal con el voltaje aplicado y los estados electrónicos del sistema punta-muestra, así como una relación exponencial con la separación entre electrodos $(\AA ̊)$ y la función de trabajo del sistema bajo estudio (eV). Debido a esta dependencia, cambios en un angstrom de separación se traducen en cambios de un orden de magnitud en corriente, fácilmente detectables para un sistema electrónico actual. Las resoluciones típicas alcanzadas hoy en día para la dirección perpendicular a la muestra, que es la que genera la tercera dimensión, son del orden de $0.1 \AA$; mientras que la resolución lateral alcanza valores que dependen principalmente del radio del ápice de la punta, cuyos valores típicos en puntas comerciales son del orden de 
$10 \mathrm{~nm}$. En el caso de puntas cuyo ápice corresponde a un átomo individual, se pueden obtener cambios en corriente del orden de pico amperes, y desplazamientos verticales en el rango de los picómetros, mientras que la resolución lateral puede alcanzar valores de $1 \AA$ (Sharma, 2016).

A pesar de que tanto la punta como la muestra requieren ser conductoras para que se lleve a cabo el proceso de tunelaje cuántico, ha sido posible realizar estudios de sistemas semi conductores y moleculares o biológicos, colocando el sistema bajo estudio entre la punta y un sustrato conductor. En el caso molecular, aunque la presencia de la molécula modifica la función de trabajo del sistema, la separación sigue siendo lo suficientemente pequeña para sostener una corriente túnel, incluso de magnitudes menores a $0.03 \mathrm{nA}$. Los arreglos moleculares que favorecen los estudios por STM consisten en estructuras planas completamente adsorbidas a un sustrato conductor en forma de moléculas individuales o monocapas autoensambladas semi-estables, o de sistemas de mayor tamaño como proteínas, en donde la molécula se ancla tanto al sustrato como a la punta a manera de puente a través de grupos funcionales (Elliot, 2018). En el primer caso, es posible no solo estudiar la morfología de arreglos supramoleculares con resolución sub-molecular, sino también las interacciones molécula-molécula y molécula-sustrato gobernadas principalmente por fuerzas intermoleculares y factores cinéticos y termodinámicos (Mali, 2017). Cabe señalar que cuando el sistema está compuesto por una interfase líquido/sólido es posible estudiar reacciones químicas en condiciones que permiten entender adicionalmente mecanismos como catálisis y fenómenos redox, entre otros (Münninghoff, 2017; Jiang, 2015).

Por otro lado, el STM se ha convertido en una herramienta indispensable para estudiar fenómenos locales de adsorción, difusión, reacción y desorción de átomos y moléculas en superficies (McKee, 2017; Mazur, 2015). Las primeras imágenes obtenidas con el STM relacionadas con la manipulación atómica, como ya se mencionó anteriormente, fueron obtenidas por Donald Eigler y Erhard Schweizer de la IBM en 1989, cuando recrearon el famoso logo de la compañía empleando átomos de xenón sobre un sustrato de níquel. Dicha hazaña requirió un tiempo de 22 horas. Actualmente, un proceso similar tomaría alrededor de 15 minutos, lo cual demuestra no solo los grandes avances de instrumentación actual, sino también, la madurez y entendimiento de los fenómenos a nanoescala. Cabe destacar que las implicaciones de estos logros, se espera tengan un impacto de manera directa en áreas relacionadas con ciencias de la computación y en el diseño de dispositivos electrónicos, entre otros. Desafortunadamente, esta implementación tecnológica no se logrará a corto plazo, pues la manipulación atómica a la fecha requiere de sistemas ultra limpios, ultra estables y a muy bajas temperaturas (menores a $4 \mathrm{~K}$ ) para su realización (Celotta, 2014).

El STM trabaja principalmente en dos modos de operación: de corriente constante y de altura constante. En el modo de corriente constante, el sistema de retroalimentación modifica la separación entre punta y muestra de 
manera precisa para mantener la corriente túnel en un valor predeterminado, proporcionando la morfología de la superficie con una alta resolución espacial. Por otro lado, en el modo de altura constante, la corriente túnel deja de depender de las variaciones en distancia, y las imágenes que se obtienen son el reflejo de variaciones en las propiedades electrónicas, pues, por sus características fundamentales, la corriente túnel muestra una alta sensibilidad a la densidad electrónica y función de trabajo de los átomos en la superficie de la muestra. Dos de las grandes ventajas de la espectroscopía realizada mediante un STM, respecto a otras técnicas espectroscópicas de superficie, son la localidad (ya que se puede realizar sobre átomos o moléculas aisladas) y el acceso a estados electrónicos tanto ocupados como vacíos de la muestra alrededor del nivel de Fermi. Esto último ha permitido el estudio de muestras a diferentes niveles de energía, en particular de las bandas de valencia y de conducción de superficies metálicas, estados electrónicos de semiconductores, óxidos de metales de transición y películas aislantes ultradelgadas, entre otros (Hamers, 1987; Schintke, 2004). Imágenes recientes de los orbitales moleculares de una molécula de pentaceno fueron obtenidas con resolución espacial inferior a un angstrom, y con tiempos de adquisición de 100 fentosegundos (Cocker, 2016). Con estos parámetros de adquisición, no solo es posible identificar estados locales sino, también, generar mapas para un nivel de energía específico en tiempo real.

Actualmente, existen muchos trabajos en donde se ve la influencia de las propiedades electrónicas en la transferencia de carga local. Sin embargo, la importancia de los estados electrónicos en estudios de química de superficies, principalmente en fenómenos de catálisis, permiten entender la correlación entre la estructura geométrica y electrónica del sistema (Weiss, 2002). De igual manera, en el caso de sistemas orgánicos, esta técnica proporciona información de los niveles de energía HOMO-LUMO. Por otro lado, la técnica de espectroscopía por tunelaje de barrido (STS) proporciona un análisis cuantitativo mediante la obtención de curvas de corriente-voltaje (I/V) en cada punto de interés de la muestra, de las cuales se obtiene la conductancia diferencial que es directamente proporcional a la densidad de estados de la superficie. En la figura 10, se muestra la morfología y las propiedades electrónicas en distintas zonas de nanotubos de carbón de pared simple funcionalizados con porfirinas de tipo polimérico sobre un sustrato de $\mathrm{Au}(111)$ (Pham, 2017). En la gráfica de conductancia diferencial, se pueden apreciar los comportamientos metálicos y semiconductores de los nanotubos. Por otro lado, estudios recientes de aluminio superconductor a ultra baja temperatura $(15 \mathrm{mK})$ han determinado que la resolución de energía depende de la interacción de la corriente túnel con el medio electromagnético y la brecha capacitiva entre punta y muestra, provocando fuentes de ruido no despreciables para esos límites de detección que son del orden de $\mu \mathrm{eV}$ (Ast, 2016). Cabe recordar que la energía térmica $\mathrm{K}_{\mathrm{B}} \mathrm{T}$ a temperatura ambiente es del orden de $26 \mathrm{meV}$ (Tantra, 2016). 
FIGURA 10. a) Imagen de STM obtenida a -1 V, 550 pA, de un nanotubo de carbón semiconductor (izq.) y un nanotubo metálico (der.) sobre una superficie de Au(111) después de un tratamiento térmico a $380 \mathrm{~K}$. Dimensiones de $35 \times 35 \mathrm{~nm}^{2}$. b) Mediciones espectroscópicas sobre las zonas de los nanotubos marcadas con símbolos de colores, en donde se muestra el comportamiento semiconductor (rojo) y metálico (negro) de los nanotubos, así como el de las especies del recubrimiento (azul) y el espectro de referencia (verde) del Au(111) con su característico estado electrónico Shockley en -0.5 V.

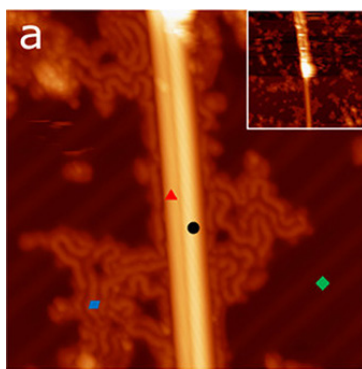

Fuente: Pham (2017); 10.1021/acs.jpcc.7b06890.

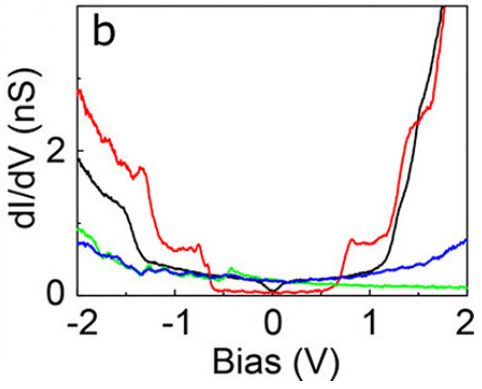

$\operatorname{Bias}(\mathrm{V})$

\section{Microscopía de fuerza atómica (AFM)}

El AFM se ha convertido en una herramienta indispensable en el estudio de superficies desde su aparición en 1986 (Binnig, 1986). A diferencia del microscopio STM, este instrumento no requiere que las muestras sean conductoras, abriendo así sus posibilidades de uso a cualquier tipo de material, como cerámicos, vidrios, polímeros, semiconductores, orgánicos y biológicos, entre muchos otros. Como su nombre lo indica, el AFM basa su funcionamiento en medir fuerzas de interacción entre los átomos de la punta sensora y la muestra, las cuales se detectan por la deflexión del soporte de dicha punta. La punta de prueba es un arreglo de cantiléver-punta, el cual se fabrica típicamente a partir de silicio $(\mathrm{Si})$ o $\mathrm{Si}_{3} \mathrm{~N}_{4}$. Dado que la forma y característica de la punta determina tanto la resolución espacial como la magnitud y tipo de fuerza medida, hoy en día existe gran interés en el desarrollo de puntas para diversas áreas de trabajo. De manera particular, se considera el compromiso entre la miniaturización, velocidad de barrido, estabilidad térmica y la sensibilidad a la deflexión, entre diversos aspectos (Rangelow, 2017). Otras formas que se han explorado para conseguir muy altas resoluciones involucran la funcionalización de las puntas, ya sea con recubrimientos especiales o incluso la adsorción de átomos o moléculas individuales $\left(\mathrm{Xe}, \mathrm{CH}_{4}\right.$, $\mathrm{CO}$, etc). Resultados recientes empleando la funcionalización de puntas no solo han mostrado resoluciones sin precedentes, sino también, la capacidad de discernir el tipo de átomo superficial bajo estudio (Sugimoto, 2007), y la estructura química de moléculas individuales identificando sus potenciales electrostáticos, orden de enlaces y radicales (Jelínek, 2017). En la figura 11, se muestran imágenes de la molécula orgánica TOAT con resolución submolecular obtenidas usando puntas con distintas funcionalizaciones. 
FIGURA 11. Imágenes de AFM de alta resolución de la molécula TOAT sobre $\mathrm{Cu}(111)$, adquiridas con puntas funcionalizadas en el modo de altura constante. A) Punta de Xe; B) Punta de CO; c) Potencial de Hartree calculado con teoría de funcionales de la densidad (DFT).
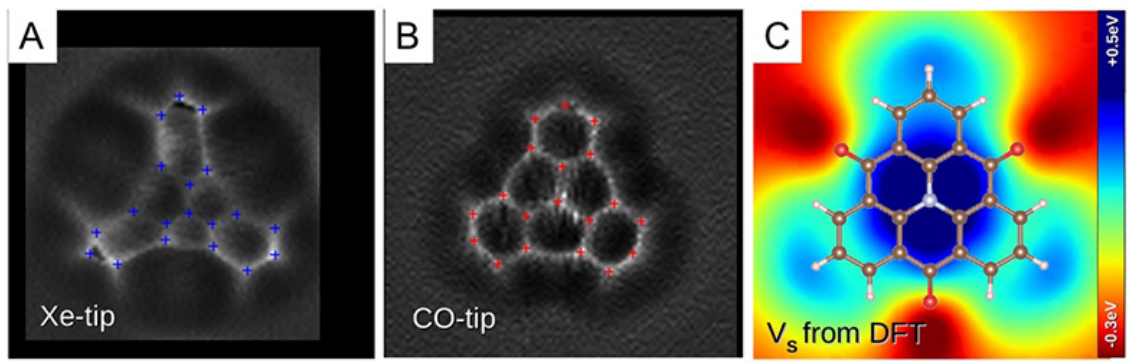

Fuente: Hapala (2016).; doi.org/10.1038/ncomms1156.

En la actualidad, se ha propuesto que el origen de la alta resolución espacial con el AFM, se debe a una combinación de fuerzas entre las que se encuentran Van der Waals que son de tipo atractivas, electrostáticas y de repulsión de Pauli, de corto alcance. Otras fuerzas que afectan las interacciones entre punta y muestra son las de adhesión, químicas, intercambio magnético, fricción, etc. El rol que juega cada una de estas fuerzas va a depender de manera directa de las características de la punta, de la muestra y del medio de trabajo. Con base en estas magnitudes de interacción, el AFM trabaja en tres modos de operación conocidos como contacto, no-contacto e intermitente; la elección entre ellos se realiza dependiendo de las características de la muestra y la información que se desea obtener del material. Por ejemplo, los materiales suaves, entre los que se encuentran los materiales orgánicos y biológicos, requieren de fuerza de interacción muy baja (menores a $10^{-9} \mathrm{~N}$ ), pues sus propiedades mecánicas cambian a escala nanométrica, debido a que el esfuerzo elástico se vuelve despreciable en comparación con fuerzas de tipo entrópicos (Haviland, 2017). Una manera de cuantificar las fuerzas punta-muestra, entre $0.3 \mathrm{~N} / \mathrm{m}$ y $400 \mathrm{~N} / \mathrm{m}$, es a través de las curvas de fuerza en donde se obtiene la fuerza como función de la distancia. Estas gráficas dan información sobre la magnitud de la adhesión, brinco a contacto, desprendimiento y muchas otras propiedades del sistema. La magnitud de las fuerzas detectadas hasta este momento es del orden de piconewtons (Zakaria, 2018; Muramatsu, 2017). Por otro lado, debido a que el AFM actúa de manera directa sobre la muestra, es posible aplicar fuerzas de forma controlada para producir efectos de indentación, rayado y desgaste para estudiar propiedades mecánicas tales como la elasticidad, fricción y dureza, entre otras. Actualmente, estas características permiten incursionar en aplicaciones como la nanolitografía y la nanomanipulación (Quian, 2004; Ternes, 2008).

Una modalidad importante del AFM es la microscopía de fuerza magnética (MFM). Esta técnica surgió al inicio de los años 90 del siglo XX, cuando se identificó la presencia de fuerzas por efecto del campo magnético en materiales ferromagnéticos durante estudios de AFM. La MFM funciona de forma 
similar al AFM, aunque formalmente opera en un modo llamado de "dos pasos", permitiendo desacoplar información morfológica y magnética, a pesar de que ambas imágenes se adquieren de manera simultánea. En esta modalidad, la sonda de barrido (en el común de los casos) consiste en una punta de AFM convencional recubierta con una aleación de cobalto-cromo ( $\mathrm{Co}-\mathrm{Cr}$ ) cuyo espesor varía entre 30-100 nm. En la actualidad, las puntas para MFM se pueden fabricar usando técnicas de depósito por haz de electrones (EBD), haz de iones focalizados (FIB) y mediante la funcionalización de la punta con nanotubos de carbón de pared múltiple (MWNT), que permiten alcanzar ápices de $5 \mathrm{~nm}$ de diámetro. A la fecha, se han alcanzado resoluciones magnéticas por debajo de los $40 \mathrm{~nm}$ (Angeloni, 2017). Por otro lado, la interacción magnética entre punta y muestra permite estudiar de manera local fuerzas de intercambio, líneas de flujo y gradientes de fuerza, así como dominios, paredes y vórtices magnéticos. Sus principales aplicaciones tecnológicas se encuentran en el área de almacenamiento de información, la caracterización de cintas magnéticas, discos duros, discos magneto-ópticos, cabezas de grabación y microalambres magnéticos, entre otros. En la figura 12, se muestra el comportamiento reversible de dominios ferroeléctricos y magnéticos en una película delgada del compuesto ferroeléctrico $\mathrm{Bi}_{5} \mathrm{Ti}_{3} \mathrm{FeO}_{15}$ como respuesta a un campo eléctrico externo. Las imágenes se obtuvieron con las técnicas AFM, VPFM, LPFM, EFM y MFM, donde se puede observar la importancia de usar técnicas complementarias para el estudio de fenómenos locales.

Como ya se mencionó, la familia de microscopios SPM es muy extensa y mediante cambios en la forma y tipo de punta, entre otros aspectos relacionados con la electrónica del sistema, es posible medir otras propiedades de los materiales tales como potenciales de superficie, conductividad eléctrica, temperatura, capacitancias, potenciales químicos, propiedades redox y piezoeléctricas, entre muchas otras, de manera local a escala nanométrica.

Por último, otra ventaja del AFM es su facilidad para acoplarse a otras técnicas de caracterización como Raman, espectroscopía infrarroja, microscopía óptica, de fluorescencia, electrónica de barrido, etc., para proporcionar información complementaria a la morfología con otras propiedades y características de la muestra (Vickery, 2001; Geisse, 2009; Dazzi, 2012; DeckertGaudig, 2017).

\section{Perspectivas}

Las técnicas de EM han avanzado de una manera vertiginosa en las útimas décadas. Hoy en día se tienen equipos con resolución sub-angstrom y aún quedan retos en el desarrollo de los EM. Uno de ellos es la aberración esférica (Cs), actualmente del orden de $0.3 \mathrm{~mm}(300 \mu \mathrm{m})$, con la que se ha logrado una resolución espacial de 50 pm; el reto puesto por Feynman en 1959 fue de $10 \mathrm{pm}$. Otro reto es la tomografía electrónica que, pese a ser una técnica utilizada en la determinación de formas tridimensionales de nanopartículas, 
www.mundonano.unam.mx | ARTículos DE REVISıón | Mundo Nano http://dx.doi.org/10.22201/ceiich.24485691e.2019.23.67334 | 12(23), 1e-25e, julio-diciembre 2019

FIGURA 12. (a-d) Imágenes topográficas obtenidas por AFM; (e-h) imágenes en ausencia de campo eléctrico obtenidas por VPFM, LPFM, MFM y EFM; (i-l); imágenes en presencia de campos eléctricos de $+20 \mathrm{~V},-20 \mathrm{~V}$ y $+20 \mathrm{~V}$ en los recuadros del centro hacia fuera, en el mismo orden de técnicas; (m-p) imágenes obtenidas a una hora de haber removido el campo eléctrico en el mismo orden de técnicas; (q-t) imágenes obtenidas a dos horas de haber removido el campo eléctrico en el mismo orden de técnicas.
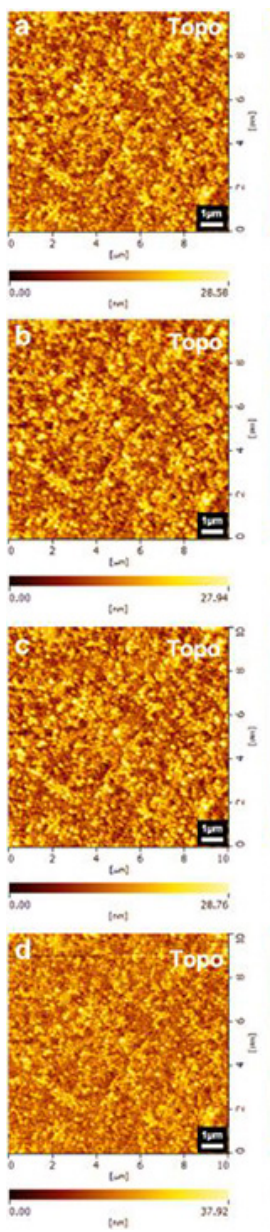
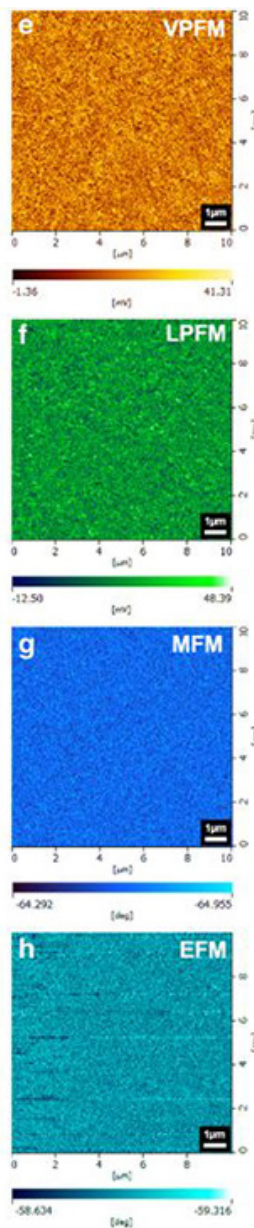
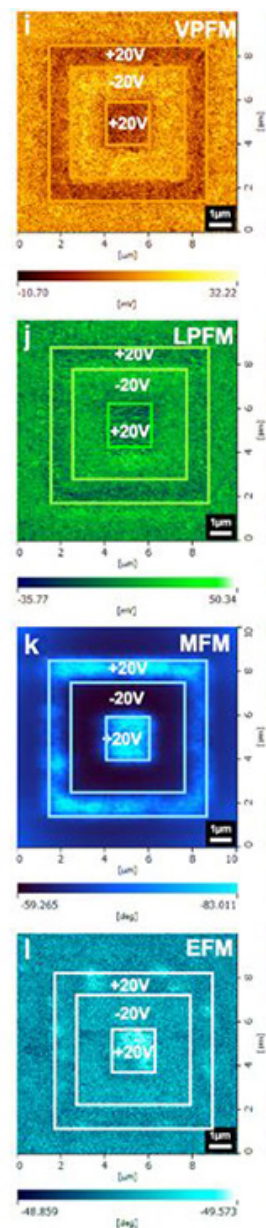
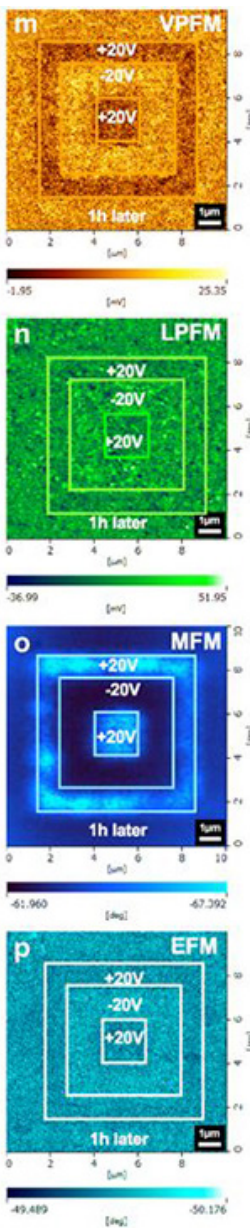
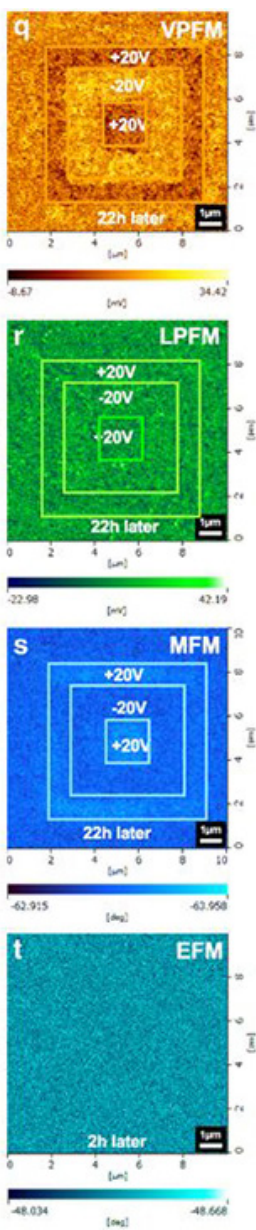

Fuente: Jia (2017); http://dx.doi.org/10.1038/am.2017.3

siendo su resolución del orden de $0.2 \mathrm{~nm}$, aún se puede mejorar. A futuro se espera también el desarrollo y mejora de un TEM ambiental, con el cual se podría dar seguimiento a experimentos en catálisis heterógenea, entre otros. En el caso de las técnicas SPM, se han logrado avances importantes en los últimos años, en la miniaturización de la puntas o sondas, y en la sensibilidad de la relación señal/ruido, lo cual ha permitido lograr velocidades de barrido por arriba de $125 \mathrm{~Hz}$, valores de ruido por debajo de $30 \mathrm{pm}$ y detecciones de fuerzas del orden de $10^{-12} \mathrm{~N}$ en equipos comerciales. Es de esperar, por el lado 
de la instrumentación que, conforme avance la tecnología tanto en el diseño de puntas como en los sistemas de detección, se logre mejorar aún más la calidad de las imágenes de acuerdo con el tipo de interacción de la técnica SPM empleada. Sin embargo, entre los grandes retos que se presentan hoy están la resolución de espín, la sensibilidad química, la visualización de moléculas complejas no planas, e incrementar la estabilidad de las muestras controlando estímulos externos y mejorando los métodos de fijación, sin comprometer las propiedades intrínsecas del material, entre muchos otros. Por otro lado, queda claro que entender los mecanismos de formación de señales (morfológicas, electrónicas, magnéticas, etc.), a nivel fundamental, es un reto abierto que requiere de entender y modelar los complejos procesos de interacción entre punta y muestra a escala nanométrica.

\section{Conclusiones}

Como se pudo observar, las técnicas de microscopía electrónica y de barrido por sonda han contribuido de manera indiscutible en el conocimiento de las propiedades y fenómenos a nanoescala. Esta información, no solo ha maravillado al ámbito científico sino que, además, ha impulsado de manera directa los procesos de miniaturización que están teniendo un impacto directo en las tecnologías de futuro, en particular, la nanotecnología.

\section{Referencias}

Angeloni, L., Passeri, D., Corsetti, S., Peddis, D., Mantovani, D. y Rossi, M. (2017). Single nanoparticles magnetization curves by controlled tip magnetization magnetic force microscopy. Nanoscale, 9(45): 18000-18011. http://dx.doi.org/10.1039/c7nr05742c

Ast, C. R., Jack, B., Senkpiel, J., Eltschka, M., Etzkorn, M., Ankerhold, J. y Kern, K. (2016). Sensing the quantum limit in scanning tunneling spectroscopy, Nature Communications, 7:13009. http://dx.doi.org/10.1038/ncomms13009

Bell, D. C. y Erdman, N. (2013). Low voltage electron microscopy: Principles and applications. 1a ed. John Wiley \& Sons Ltd. ISBN: 978-1-119-97111-5. Reino Unido: West Sussex.

Binnig, G. y Rohrer, H. (1982). Scanning tunneling microscopy. Helvetica Acta, 55: 726-735.

Binnig, G., Quate, C. F. y Gerber, Ch. (1986). Atomic force microscope. Physical Review Letters, 56: 930. http://dx.doi.org/10.1103/PhysRevLett.56.930

Borrajo-Pelaez, R. y Hedström, P. (2018). Recent developments of crystallographic analysis methods in the scanning electron microscope for applications in metallurgy. Critical Reviews in Solid State and Materials Sciences. 43: 455-474. http://dx.doi.org/10.1080/10408436.2017.1370576

Celotta, R. J., Balakirsky, S. B., Fein, A. P., Hess, F. M., Rutter, G. M. y Stroscio, J. A. (2014). Autonomous assembly of atomically perfect nanostructures using a 
scanning tunneling microscope. Review of Scientific Instruments, 85: 121301. http://dx.doi.org/10.1063/1.4902536

Chen, C. C., Zhu, C., White, E. R, Chiu, C. Y., Scott, M. C., Regan, B. C., Marks, L. D., Yu Huang, Miao J., (2013). Three-dimensional imaging of dislocations in a nanoparticle at atomic resolution. Nature. 496: 74-79.

http://dx.doi.org/10.1038/nature12009

Cocker, T.L., Peller, D., Yu, P., Repp, J. y Huber, R. (2016). Tracking the ultrafast motion of a single molecule by femtosecond orbital imaging. Nature, 539:263-267. http://dx.doi.org/10.1038/nature19816

Dazzi, A., Prater, C. B., Hu, Q., Chase, D. B., Rabolt, J. F. y Masrcott, C. (2012). AFMIR: Combining atomic force microscopy and infrared spectroscopy for nanoscale chemical characterization. Applied Spectroscopy, 66(12): 1365-1384. http://dx.doi.org/10.1366/12-06804

Deckert-Gaudig, T., Taguchi, A., Kawata, S. y Deckert, V. (2017). Tip-enhanced Raman spectroscopy - from early developments to recent advances. Chemical Society Reviews, 46: 4077-4110. http://dx.doi.org/10.1039/C7CS00209B

Elliot, M. y Jones, D. D. (2018). Approaches to single-molecule studies of metalloprotein electron transfer using scanning probe-based techniques. Biochemical Society Transactions, 46: 1-9. http://dx.doi.org/10.1042/BST20170229

Geisse, N. A. (2009). AFM and combined optical techniques. Materials Today, 12(7-8): 40-45. http://dx.doi.org/10.1016/S1369-7021(09)70201-9.

Giannuzzi, L. A. y Stevie F. A. (1999). A review of focused ion beam milling techniques for TEM specimen preparation. Micron 30: 197-204. PII: S0968-4328(99)00005-0.

Grillo, V. y Rotunno, E. (2013). STEM_CELL: A software tool for electron microscopy: Part I - simulations. Ultramicroscopy 125: 97-111. http://dx.doi.org/10.1016/j.ultramic.2012.10.016

Hamers, R. J., Tromp, R. M. y Demuth, J. E. (1987). Electronic and geometric structure of $\mathrm{Si}(111)-(7 \times 7)$ and $\mathrm{Si}(001)$ surfaces. Surface Science, 181(1-2): 346-355. http://dx.doi.org/10.1016/0039-6028(87)90176-2

Haviland, D. B. (2017). Quantitative force microscopy from a dynamic point of view. Current Opinion in Colloid \& Interface Science, 27: 74-81.

http://dx.doi.org/10.1016/j.cocis.2016.10.002

Jelínek, P. (2017). High resolution SPM imaging of organic molecules with functionalized tips. Journal of Physics: Condensed Matter, 29: 343002. http://dx.doi.org/10.1088/1361-648X/aa76c7

Jia, T., Kimura, H., Cheng, Z., Zhao, H., Kim,Y.-H., Osada, M., Matsumoto, T., Shibata, N. y Ikuhara, Y. (2017). Mechanical force involved multiple fields switching of both local ferroelectric and magnetic domain in a $\mathrm{Bi}_{5} \mathrm{Ti}_{3} \mathrm{FeO}_{15}$ thin film. NPG Asia Materials, 9: e349. http://dx.doi.org/10.1038/am.2017.3

Jiang, P., Bao, X. y Salmeron, M. (2015). Catalytic reaction processes revealed by scanning probe microscopy. Accounts of Chemical Research, 48(5): 1524-1531. http://dx.doi.org/10.1021/acs.accounts.5b00017

Kirkland, E. J. (2009). Advanced computing in electron microscopy. Springer Science+Business Media, LLC. 
Levi-Setti, R. (1974). Proton scanning microscopy: feasibility and promise. Scanning Electron Microscopy, 125-134.

Mali, K. S., Pearce, N., De Feyter, S. y Champness, N. R. (2017). Frontiers of supramolecular chemistry at solid surfaces. Chemical Society Reviews, 46: 2520. http://dx.doi.org/10.1039/c7cs00113d

Mazur, U. y Hipps, K. W. (2015). Kinetic and thermodynamic processes of organic species at the solution-solid interface: the view through an STM. Chemical Communications, 51: 4737-4749. http://dx.doi.org/10.1039/C4CC09840D

McKee, W. C., Patterson, M. C., Frick, J. R., Sprunger, P. T. y Xu, Y. (2017). Adsorption of transition metal adatoms on h-BN/Rh(111): Implications for nanocluster self-assembly. Catalysis Today, 280: 220-231.

http://dx.doi.org/10.1016/j.cattod.2016.09.030

Mcmullan, D. (1995). Scanning electron microscopy 1928-1965*. Scanning, 17: 175-185.

Merkle, R. (2018). There's plenty of room at the bottom. http://www.zyvex.com/nanotech/ feynman.html (Consultado, septiembre 4, 2018).

Münninghoff, J. A. W. y Elemans, J. A. A. W. (2017). Chemistry at the square nanometer: reactivity at liquid/solid interfaces revealed with an STM. Chemical Communications, 53: 1769. http://dx.doi.org/10.1039/c6cc07862a

Muramatsu, H., Shimada, S. y Okada, T. J. (2017). Direct measurement of interaction forces between a platinum dichloride complex and DNA molecules. Journal of Biological Physics, 43: 355. http://dx.doi.org/10.1007/s10867-017-9456-5

Oxley, M. P., Lupini, A. R. y Pennycook, S. J., (2017). Ultra-high resolution electron microscopy. Reports on Progress Physics, 80(2): 026101.

http://dx.doi.org/10.1088/1361-6633/80/2/026101

Pennycook, S. J., Li, C., Li, M., Tang, C., Okunishi, E., Varela, M., Kim, Y. y Jang J. (2018). Material structure, properties, and dynamics through scanning transmission electron microscopy. Journal of Analytical Science and Technology, 9: 11. http://dx.doi.org/10.1186/s40543-018-0142-4

Pennycook, S. J., Varela, M., Hetherington, C. J. D. y Kirkland, A. I. (2006). Materials advances through aberration- corrected electron microscopy. MRS Bulletin, 31: 36-43. http://dx.doi.org/10.1557/mrs2006.4

Pham, V. D., Repain, V., Chacon, C., Bellec, A., Girard, Y., Rousset, S., Campidelli, S., Lauret, J.-S., Voisin, C., Terrones, M., Dos Santos, M. C. y Lagoute, J. (2017). Properties of functionalized carbon nanotubes and their interaction with a metallic substrate investigated by scanning tunneling microscopy. The Journal of Physcial Chemistry C. 121(43): 24264-24271.

http://dx.doi.org/10.1021/acs.jpcc.7b06890

Qian, T. San-Qiang, S. y Limin, Z. (2004). Nanofabrication with atomic force microscopy. Journal of Nanoscience and Nanotechnology, 4(8): 948-963.

http://dx.doi.org/10.1166/jnn.2004.131.

Rangelow, I. W., Ivanov, T., Ahmad, A., Kaestner, M., Lenk, C., Bozchalooi, I. S., Xia, F., Youcef-Toumi, K., Holz, M. y Reum, A. (2017). Active scanning probes: A versatile toolkit for fast imaging and emerging nanofabrication. Journal of Vacuum Science \& Technology B, 35: 06G101. http://dx.doi.org/10.1116/1.4992073 
Schintke, S. y Schneider, D. (2004). Insulators at the ultrathin limit: electronic structure studied by scanning tunnelling microscopy and scanning tunnelling spectroscopy. Journal of Physics: Condensed Matter, 16: R49.

http://dx.doi.org/10.1088/0953-8984/16/4/R02

Schitter, G. y Rost, M. J. (2008). Scanning probe microscopy at video-rate. Materials Today, 11: 40-48. http://dx.doi.org/10.1016/S1369-7021(09)70006-9

Sharma P. y Seidel J. (2016). Scanning probe microscopy of functional materials surfaces and interfaces. En Ashutosh Tiwari, Hirak K. Patra y Xuemei Wang (eds.), Advance Materials Interfaces. Scrivener Publishing LLC., 63-114.

Stewart, P. L. (2017). Cryo-electron microscopy and cryo-electron tomography of nanoparticles. WIREs Nanomed Nanobiotechnol, 9: e1417.

http://dx.doi.org/10.1002/wnan.1417

Sugimoto, Y., Pou, P., Abe, M., Jelinek, P., Pérez, R., Morita, S. y Custance, O. (2007). Chemical identification of individual surface atoms by atomic force microscopy. Nature (Letter), 446(7131): 64-67. http://dx.doi.org/10.1038/nature05530

Tantra, R., (2016). Nanomaterial characterization: An introduction. John Wiley and Sons, Inc. ISBN: 9781118753590.

Ternes, M., Lutz, C. P., Hirjibehedin, C. F., Giessibl, F. J., Heinrich, A. J. (2008). The force needed to move an atom on a surface. Science, 319: 1066. http://dx.doi.org/10.1126/science.1150288

Van Aert, S., Batenburg, K. J., Rossell, M. D., Rolf, Erni y Van Tendeloo, G. (2011). Three-dimensional atomic imaging of crystalline nanoparticles. Nature. http://dx.doi.org/10.1038/nature09741

Varela, M., et al. (2004). Spectroscopic imaging of single atoms within a bulk solid. Physical Review Letters, 92: 095502-1 - 095502-4.

http://dx.doi.org/10.1103/PhysRevLett.92.095502

Vickery, S. A. y Dunn, R. C. (2001). Combining AFM and FRET for high resolution fluorescence microscopy. Journal of Microscopy, 202(2): 408-412. http://dx.doi.org/10.1046/j.1365-2818.2001.00857.x

Weiss, W. y Ranke, W. (2002). Surface chemistry and catalysis on well-defined epitaxial iron-oxide layers. Progress in Surface Science, 70: 1-151.

http://dx.doi.org/10.1016/S0079-6816(01)00056-9

William, D. B., Carter, B. (2009). Transmission electron microscopy: A textbook for materials science. 2a ed. Springer. ISBN 978-0-387-76502-0, Nueva York, USA.

Zakaria, N. S., Aziz, A. A. (2018). Effect of medium on interaction forces between atomic force microscopy (AFM) tip and gold nanoparticle. Journal of Physics: Conference Series, 1083(1): 012035.

http://dx.doi.org/10.1088/1742-6596/1083/1/012035

\section{Acrónimos (por sus siglas en inglés):}

ADF - Campo oscuro anular (Annular dark field).

AFM - Microscopía de fuerza atómica (Atomic force microscopy). 
C-AFM - Microscopía de fuerza atómica conductora (Conductive atomic force microscopy).

CBED - Difracción de electrones por haz convergente (Convergent beam electron diffraction).

CFM - Microscopía de fuerza química (Chemical force microscopy).

CITS - Espectroscopía de tunelamiento de imágenes de corriente (Current imaging tunneling spectroscopy).

CTEM - Microscopía electrónica de transmisión convencional (Conventional transmission electron microscopy).

DFTEM - Campo oscuro por microscopía electrónica de transmisión (Dark field transmission electron microscopy).

EBSD - Difracción de electrones retrodispersados (Electron backscatter diffraction).

EDS - Espectroscopía por dispersión de energía de rayos X (Energy dispersive X-ray spectroscopy).

EELS - Espectroscopía por pérdida de energía por electrones (Electron energy loss spectroscopy).

EFM - Microscopía de fuerza electrostática (Electrostatic force microscopy).

EM - Microscopía electrónica (Electron microscopy).

ESEM - Microscopía electrónica de barrido ambiental (Environmental scanning electron microscopy).

FIB - Haz de iones focalizados (Focus ion beam).

FFM - Microscopía de fuerza de fricción (Friction force microscopy).

FMM - Microscopía de modulación de fuerza (Force modulation microscopy).

FSEM - Microscopía electrónica de barrido de emisión de campo (Field emission electron microscopy).

HAADF - Campo oscuro anular a ángulo grande (High angle annular dark field).

HR-HAADF - Campo oscuro anular a ángulo grande en alta resolución (High resolution - High angle annular dark field).

HRTEM - Microscopía electrónica de alta resolución (High resolution transmission electron microscopy).

KFM - Microscopía de fuerza Kelvin (Kelvin force microscopy).

LFM - Microscopía de fuerza lateral (Lateral force microscopy).

LPFM - Microscopía de fuerza piezorrespuesta lateral (Lateral piezoresponse force microscopy).

LV-SEM - Microscopía electrónica de barrido de bajo vacío (Low vacuum scanning electron microscopy).

$\mu$-Raman - Micro-Raman (Micro-Raman).

MFM - Microscopía de fuerza magnética (Magnetic force microscopy).

NC-AFM - Microscopía de fuerza atómica de no contacto (Non-contact atomic force microscopy).

PRFM - Microscopía de respuesta piezoeléctrica (Piezoresponse force microscopy).

PSTM - Microscopía de tunelamiento de barrido por fotones (Photon scanning tunneling microscopy).

SCM - Microscopía capacitiva de barrido (Scanning capacitance microscopy). 
SECM - Microscopía electroquímica de barrido (Scanning electrochemical microscopy).

SEM - Microscopía electrónica de barrido (Scanning electron microscopy).

SFS - Espectroscopía de fuerza de barrido (Scanning force spectroscopy).

SHPM - Microcoscopía de sonda de barrido de efecto hall (Scanning hall probe microscopy).

SICM - Microscopía de barrido de conductancia de iones (Scanning ion conductance microscopy).

SNOM - Microscopía óptica de barrido de campo cercano (Scanning near-field optical microscopy).

SPM - Microscopía de barrido por sonda (Scanning probe microscopy).

SP-STM - Microscopía de efecto tunel de polarización de spin (Spin-polarized scanning tunneling microscopy).

STEM - Microscopía electrónica de transmisión por barrido (Scanning transmission electron microscopy).

SThM - Microscopía térmica de barrido (Scanning thermal microscopy).

STM - Microscopía de efecto tunel (Scanning tunneling microscopy).

STP - Potenciometría de barrido por tunelaje (Scanning tunneling potentiometry).

STS - Espectroscopía de tunelamiento de barrido (Scanning tunneling spectroscopy).

SVM - Microscopía de barrido de voltage (Scanning voltage microscopy).

TEM - Microscopía electrónica de transmisión (Transmission electron microscopy).

VPFM - Microscopía de fuerza piezorespuesta vertical (Vertical piezorresponse force microscopy).

WDS - Espectroscopía por dispersión de longitud de onda (Wavelength dispersive spectroscopy).

XRF - Fluorescencia de rayox X (X-ray fluorescence). 